\title{
Editorial
}

\section{The Journal of Applied Oral Science welcomes the Co-Editor-in-Chief}

Dear Readers, Contributors and Reviewers,

It is a great pleasure to announce that Professor José Carlos Pereira, Dean of the Bauru School of Dentistry, appointed Dr. Gustavo P. Garlet as the Co-Editor-in-Chief of the Journal of Applied Oral Science.

Dr. Garlet earned his DDS degree from the University of Ponta Grossa in 1999. He obtained his MSc and PhD in Basic and Applied Immunology from the School of Medicine of Ribeirão Preto, University of São Paulo, in the years of 2002 and 2005, respectively. He was a postdoctoral fellow at the Department of Biochemistry and Immunology of the same institution in 2005, and at the Center for Craniofacial and Dental Genetics, Department of Oral Biology, School of Dental Medicine, University of Pittsburgh, in 2008. Currently, he is an Associate Professor at the Department of Biological Sciences of the Bauru School of Dentistry, University of São Paulo. Dr. Garlet is a brilliant scientist, and serves as reviewer for many peer-review journals. He was awarded the Clinical Impact Award of the American Academy of Periodontology, in 2010, and the American Society for Bone and Mineral Research Annual Meeting President's Competition Award, in 2011. He has expertise in the areas of immunology and histology.

The whole team of the Journal of Applied Oral Science is enthusiastic with the new CoEditor-in-Chief, and foresees a great deal of improvements in the journal in the near future. Dr. Garlet will work directly with the Editor-inChief, and both will have the same level of power in the reviewing and decision process of the articles submitted to our journal.

The Journal of Applied Oral Science welcomes Dr. Garlet. We are confident that he will do a great job in making our publication an even better journal at the service of dental research.

Yours sincerely,

\author{
Carlos F. Santos \\ Editor-in-Chief \\ Journal of Applied Oral Science
}

